\title{
Continental collision, gravity spreading, and kinematics of Aegea and Anatolia
}

\author{
J. Martinod ${ }^{1}$ and D. Hatzfeld \\ Laboratoire de Géophysique Interne et Tectonophysique, Observatoire de Grenoble, Grenoble, \\ France
}

\author{
J.P. Brun, P. Davy, and P. Gautier \\ Géosciences Rennes, Université de Rennes 1, Rennes, France
}

\begin{abstract}
We have carried out experiments using a layered medium of sand and silicone to investigate the lateral extrusion of a material which spreads over its own weight while being compressed by the advance of a rigid indenter. Boundary conditions in the box mimic those prevailing in the Anatolian-Aegean system. Both shortening in front of the rigid piston, which models the northward motion of Arabia, and extension resulting from the gravity spreading of the sand-silicone layer are necessary to initiate the lateral extrusion. Strike-slip faults accommodate the lateral escape and link the normal faults accompanying gravity spreading with the thrust faults in front of the rigid indenter. Strike-slip faults begin to accommodate extrusion at a late stage in the experiments after the normal and thrust faults have developed. Experiments also show that the initial geometry of the boundary of the spreading layer may result in the formation of two arcs behind which material extends, in a manner analogous to the Hellenic and Cypriot arcs, without invoking a rheological change at the junction of the two arcs. The experiments also suggest that southward motion of the eastern part of the spreading region is compensated by the northward advance of the piston, which is a possible explanation for the slower movement of the Cypriot arc compared to the Aegean arc.
\end{abstract}

\section{Introduction}

While the present-day kinematics of the Anatolian-Aegean system are now well constrained by geodetic Global Positionning System (GPS) and Satellite Laser Ranging (SLR) measurements [e.g., Noomen et al., 1994; Oral, 1994; Veis et al., 1992; Le Pichon et al., 1995; Reilinger et al., 1997] (Figure 1), the tectonic processes responsible for the westward motion of the AnatolianAegean plate are still a subject of debate. Following McKenzie [1972], most authors consider the westward movement of Anatolia with respect to Eurasia to be the result of the continental collision between Eurasia and Arabia, because extrusion minimizes the thickening of the continental crust in front of the Arabian indenter. It is worth noting, however, that if the Anatolian-Aegean plate bears a compressive tectonic regime on its eastern side resulting from the Arabia-Eurasia continental collision, it also bears extension deformation in its western half. Although the present-day rapid southwestward motion of the Aegean with respect to stable Europe (Figure 1) is consistent with the lateral escape of Anatolia to the west [e.g., Le Pichon et al., 1995; Armijo et al., 1996], the thinning of the Aegean plate developed in response to local forces, such as the forces generated by the subducted Mediterranean oceanic lithosphere or those resulting from the topography and thickness of the Aegean plate at the end of the Hellenic orogenesis [e.g., Berckhemer, 1977; Le Pichon and Angelier, 1979; England et al., 1985; Sonder and England, 1989; Meijer and Wortel, 1996; Lundgren et al., 1998]. This extension first developed independently of the Arabia-Eurasia collision. As a matter of fact, it started in Cyclades as early as early Miocene [Lister et al., 1984; Jolivet et al., 1994; Gautier 
and Brun, 1994], which is more than 10 Myr older than the Arabia-Eurasia collision [Gautier et al., 1999]. The arcuate form of the Hellenic trench turning from NNW-SSE in western Greece to NE-SW off Rhodos, the Neogene clockwise rotations in western Greece, the counterclockwise rotations in western Turkey [Kissel and Laj, 1988], and the present-day extension parallel to the trench in the Hellenic arc [e.g., Hatzfeld et al., 1990, 1993; Kahle et al., 1998] highlight the influence of gravity spreading of the continental plate above the eastern Mediterranean in the internal deformation of the Aegean [e.g., Le Pichon and Angelier, 1979; Sonder and England, 1989; Hatzfeld et al., 1997; Gautier et al., 1999].

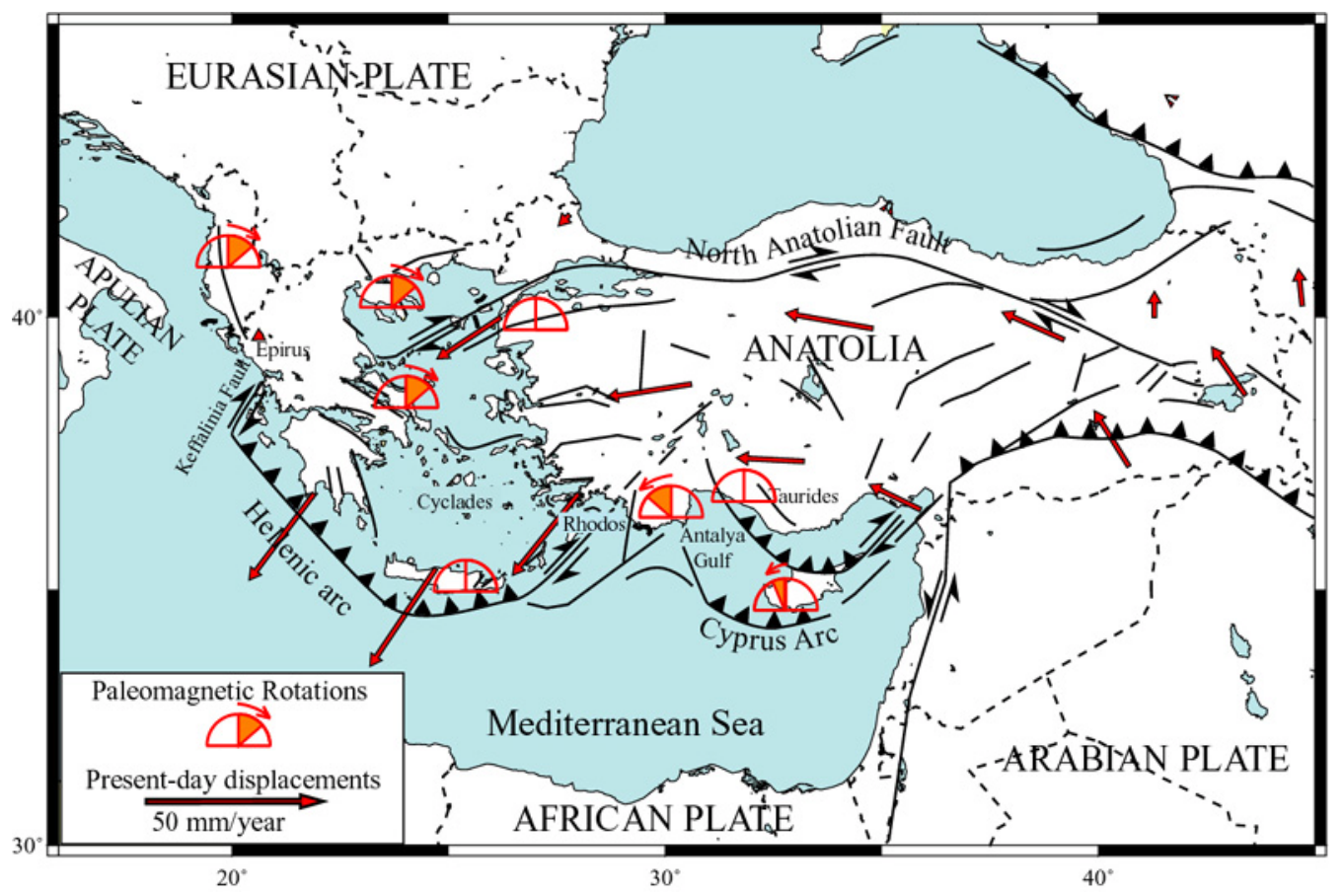

Figure 1. Tectonics of the Anatolian-Aegean area. Present-day displacements are obtained from Reilinger et al. [1997]. Rotations are from the paleomagnetic data presented by Abrahamsen and Schönharting [1987], Kissel and Laj [1988], Kissel et al. [1993], and Speranza et al. [1995].

In the following, we present simple analogue experiments that simulate the Arabia-Eurasia collision, the Aegean extension, and the lateral escape of Anatolia, in order to study two points:

1. The first point is the effect of the compression applied on the eastern border of Anatolia, and of the forces generated near the Aegean that favor extension, on the motion of Anatolia. Experiments suggest that the lateral escape of Anatolia results from both the Arabia-Eurasia collision and the Aegean back- arc tension forces and that lateral escape could not occur without the two phenomena acting together.

2. The second point is the role of the boundary conditions exerted in the eastern Mediterranean: Experiments show that the initial geometry of the spreading layers partly controls their finite deformation and rotation and may explain the formation of several spreading arcs above the oceanic plate 


\section{Analogue Experiments}

We use relatively simple analogue experiments simulating the Anatolian-Aegean tectonics, to study first-order tectonic phenomena in the area. For convenience, we shall refer to regions of the analogue experiment in terms of geographical directions (north, south, east, and west). The lithosphere in the Anatolian, Aegean, and European regions is modeled by a dry sand layer underlain by a silicone layer. The absence of cohesion and internal friction angle of the dry sand make it an analogue for the brittle upper crust, while the silicone putty simulates the ductile lower lithosphere (see the work of Davy and Cobbold [1991] for details concerning scaling in this kind of experiments). These layers float above a liquid (honey) representing the asthenosphere, whose viscosity of about $20 \mathrm{~Pa} \mathrm{~s}$, is negligible compared to the viscosity of silicone (Table 1). We did not include any details in the layers modeling the lithosphere to preserve the simplicity of the experiment. The sand and silicone layers are slightly lighter than the honey $(1200 \mathrm{~kg} / \mathrm{m} 3$ versus $1400 \mathrm{~kg} / \mathrm{m3}$; see Table 1) to simulate a floating continental lithosphere above the asthenosphere. Above the sand layer, a rectangular grid of passive colored-sand markers enables visualization of the deformation. The deformed grid is then digitized at different steps of the experiment to monitor the total and incremental displacements, deformation, and rigid rotations.

\begin{tabular}{|c|c|c|c|c|c|c|c|c|c|c|c|}
\hline Experiment & $\begin{array}{c}\mathrm{H}_{\text {sand }} \\
\mathrm{mm}\end{array}$ & $\begin{array}{c}\mathrm{H}_{\text {silicone }} \\
\mathrm{mm}\end{array}$ & $\begin{array}{c}\rho_{\text {sand, }} \\
\mathrm{kg} / \mathrm{m}^{3}\end{array}$ & $\begin{array}{l}\rho_{\text {silicone, }} \\
\mathrm{kg} / \mathrm{m}^{3}\end{array}$ & $\begin{array}{l}\rho_{\text {honey, }} \\
\mathrm{kg} / \mathrm{m}^{3}\end{array}$ & $\begin{array}{l}\eta_{\text {silicone, }} \\
\text { Pa s }\end{array}$ & $\begin{array}{l}\text { Door Width, } \\
\mathrm{mm}\end{array}$ & $\begin{array}{c}\text { Piston Width, } \\
\mathrm{mm}\end{array}$ & $\begin{array}{c}\text { Piston Speed, } \\
\mathrm{mm} / \mathrm{h}\end{array}$ & $\begin{array}{c}\text { Sand Strength, } \\
N / \mathrm{m}\end{array}$ & $\begin{array}{c}\text { Spreading } \\
\text { Force, } \mathrm{N} / \mathrm{m}\end{array}$ \\
\hline \multicolumn{12}{|l|}{1} \\
\hline (reference) & 8 & 22 & 1200 & 1200 & 1400 & $3 \times 10^{4}$ & 200 & 200 & 100 & 0.26 & 0.77 \\
\hline \multicolumn{12}{|l|}{2} \\
\hline (large door) & 8 & 20 & 1200 & 1200 & 1400 & $3 \times 10^{4}$ & 650 & 250 & 60 & 0.26 & 0.67 \\
\hline \multicolumn{12}{|l|}{3} \\
\hline (no spreading) & 8 & 12 & 1400 & 1350 & 1400 & $3 \times 10^{4}$ & 200 & 200 & 30 & 0.30 & 0.08 \\
\hline
\end{tabular}

Table 1. Experimental Parameters : In Experiments 1 and 2 the silicone and sand layers are significantly lighter than honey. As a consequence, gravity spreading occurs. In Experiment 3, forces arising from density contrasts are not large enough to break the sand layer.

The Mediterranean oceanic plate is simply modeled by honey without any other material above it. We are not interested here in examining the deformation of the oceanic plate but only in simulating the gravity spreading of the continental lithosphere above the subducting ocean [Hatzfeld et al., 1997].

\section{Boundary Conditions}

The sand-silicone plate is placed in a rectangular box (Figure 2). Tensional forces pull the southern boundary of the sand-silicone layer, because of the different buoyancy of the sand, silicone, and honey. When the forces arising from these density contrasts are large enough to break the sand layer, gravity spreading of the sand-silicone plate starts (Table 1). In nature the extension of the continental lithosphere above the retreating oceanic slab results from many other phenomena, as, for example, trench suction, which are not modeled here to preserve the simplicity of the experiments. 
Crossing the box in the middle, a wall bounds the sand-silicone layer. At the beginning of the experiment, part of this wall is removed (Figure 2), and the light sand-silicone layer starts to spread over the honey, simulating the spreading of the continental lithosphere over the subduction zone. Note that the initial boundary of the spreading sand-silicone plate is not straight but angled at the eastern end.

Figure 2. Boundary conditions for the analogue experiments. Thick lines represent rigid walls, and the thin line is the free boundary of the spreading sand-silicone layer.

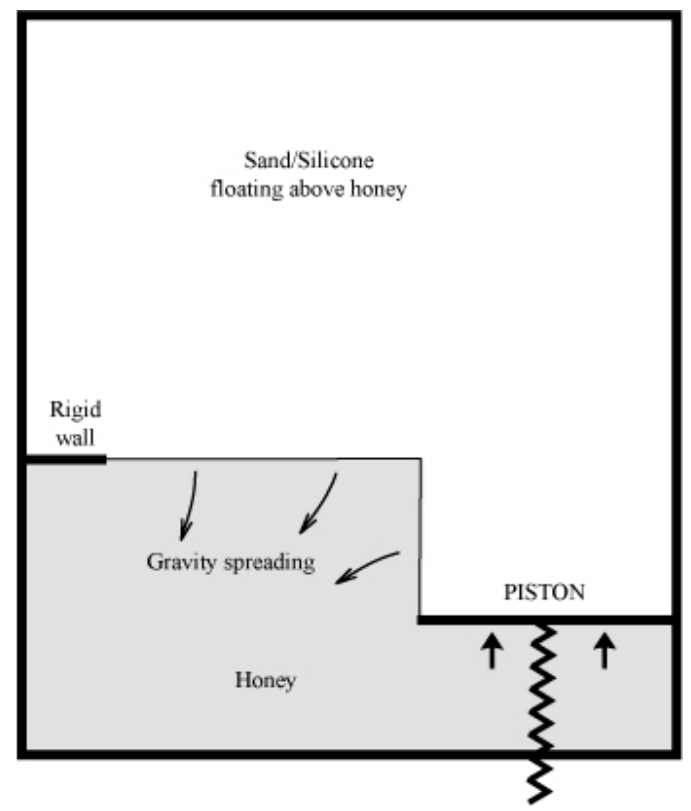

A rigid indenter placed in the southeastern part of the box moves in the northward direction at a constant speed (a few centimenters per hour; see Table 1) to simulate the northward motion of Arabia with respect to stable Eurasia. On the other side of the box a small wall is placed to model the Apulian continental plate. In the experiment this wall does not move. We do not take into account the motion of Apulia with respect to Europe, because this motion is slower than the displacement of Arabia and also because Apulia is much smaller than Arabia. Thus it is assumed that the motion of Apulia is not responsible for the first-order structures that develop in the Anatolian-Aegean system. The other walls of the box are rigid. Their geometry does not have any influence on the deformation, since the deformed area is always confined in a small domain in the center of the box as England et al. [1985] predicted (see Figure 3). The advance of the rigid indentor starts at the beginning of the experiment, simultaneously with initiation of spreading of the sand-silicone layer. The speed of the piston is chosen to be roughly similar to the speed of the spreading sand-silicone layer over the honey, because in reality the speed of Arabia to the north is comparable with the speed of the Hellenic arc to the SW.

In section 4, we present only three different analogue experiments, although many more were built. The precise geometry of the faults that appear in the experiments we present, compared to similar ones we do not describe here, may not be exactly the same. The strain regime that develops in both experiments is, however, essentially the same, and the observations we discuss in section 5 have been reproduced in several experiments.

\section{The Development of Lateral Escape in Experiments}

As soon as the rigid wall constraining the sand-silicone layer is removed, spreading starts. Because of the initial geometry of the spreading layer, two arcs develop, both generated by 
several families of faults (Experiment 1, Figure 3). At the beginning of deformation during the first 20 min of Experiment 1, E-W normal faults develop near the E-W free boundary. Two families of conjugate strike-slip faults with a normal dip-slip component also develop within two oblique areas on both sides of this free boundary (Figure 3B). We observe a geometry of faults in this region similar to that obtained by Hatzfeld et al. [1997] or Gautier et al. [1999] in gravity spreading experiments without a moving piston. This result indicates that the westernmost arc that initially develops from the E-W boundary is not influenced by the advance of the piston.

a

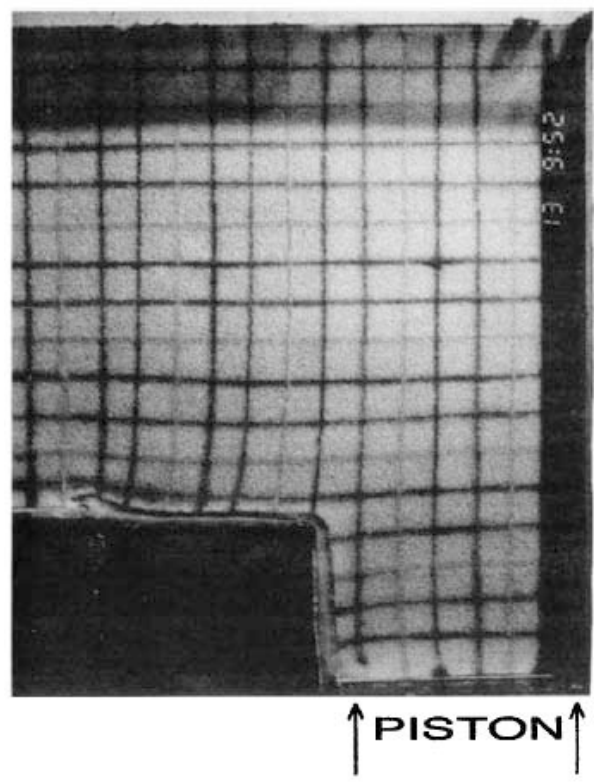

$\mathrm{c}$

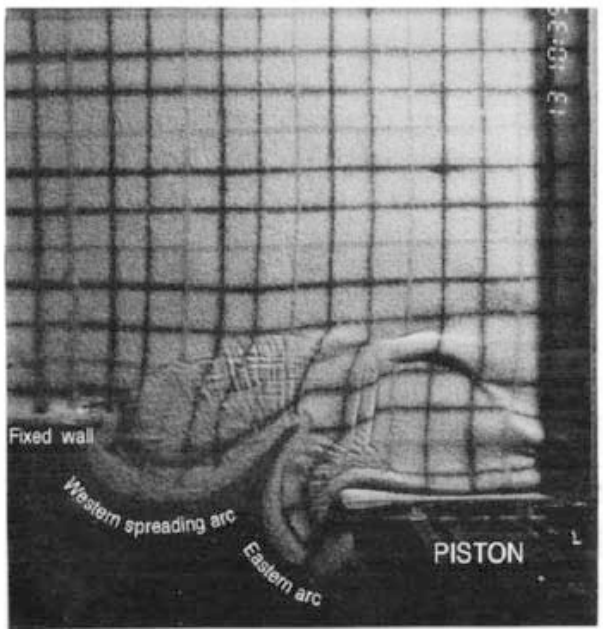

b

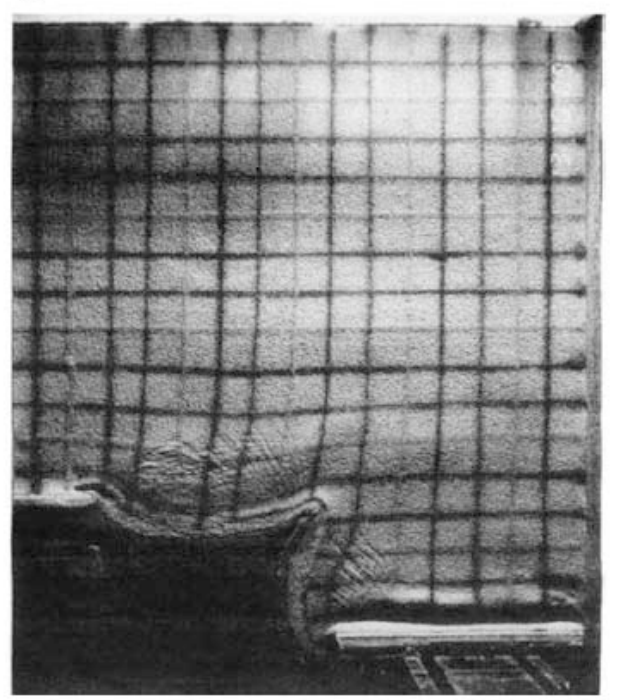

d

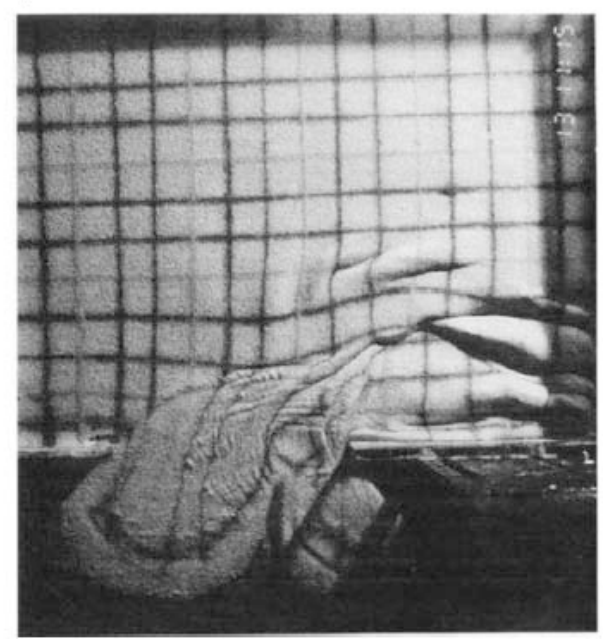

Figure 3. Top view of the reference experiment (Experiment 1; see Table 1) at different stages of deformation. (a) Beginning of experiment. The wall maintaining the sand-silicone layer has just been removed. (b) After 18 min of experiment. The spreading of the two arcs has started, and the shortening is concentrated very near the piston. Lateral escape still does not occur. (c) After 43 min of experiment. Dextral strike-slip faults accommodating the lateral extrusion have appeared. These faults join the thrusts in front of the piston with the grabens situated on the western side of the experiment. (d) After 83 min of experiment. The new thrusts in front of the piston appear too far north of the stretched zone to be connected to the grabens. There is no more lateral extrusion. (e) Line drawing of the main faults in the experiment after 43 min. 
Figure 3 (continued) : Figure $3 e$

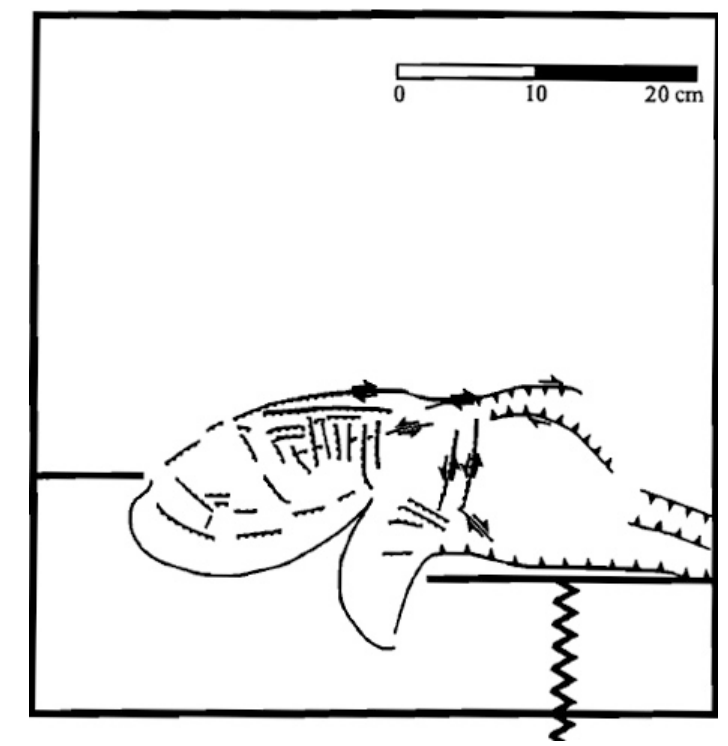

In Figure 4 the motion of passive markers situated on the boundary of the western arc is mapped. During the first $20 \mathrm{~min}$ of the experiment, we observe that the markers start to diverge and that the spreading boundary develops an arcuate geometry. During that time, the passive markers move to the south, showing that lateral escape has not started, or at least, that it does not influence the deformation of the western part of the spreading layers.

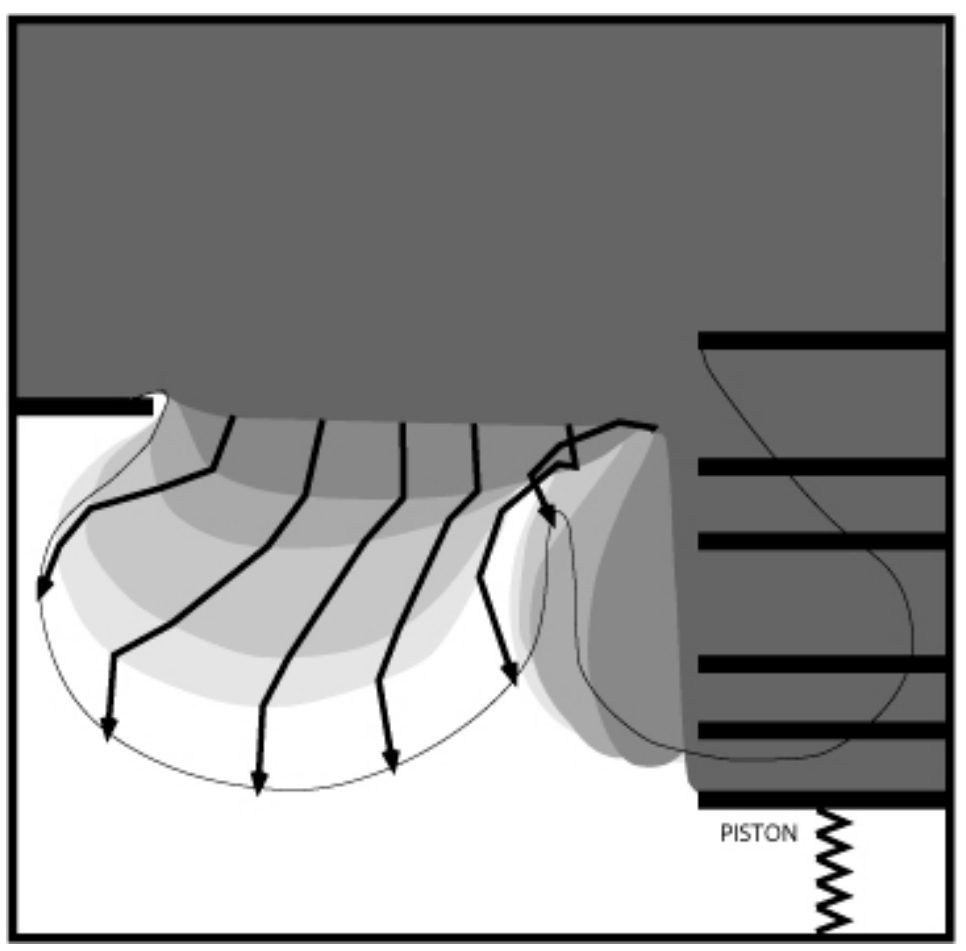

at the beginning of experiment

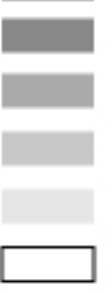
after $18 \mathrm{mn}$ of experiment after $33 \mathrm{mn}$ of experiment after $58 \mathrm{mn}$ of experiment after $73 \mathrm{mn}$ of experiment after $98 \mathrm{mn}$ of experiment

Figure 4. Displacement of passive markers on the western spreading arc in Experiment 1. At the beginning of the experiment (between 0 and $18 \mathrm{~min}$ ), markers move to the south, showing that lateral escape has not started. During the interval 18-73 min, lateral escape prevails, and markers move to the southwest. At the end of the experiment, lateral escape has stopped, and markers move again to the south. 
Between 20 and 70 min the shortened area in front of the piston grows northward. Dextral EW strike-slip faults appear in the area situated between the shortened zone and the western arc (Figure 3). Figure 5 shows the incremental displacements of the nodes of the grid during this time period. Nodes situated in front of the piston move to the north, while nodes situated north of the eastern arc move to the west, and nodes situated within the western arc move to the southwest (Figure 4). This indicates that the shortening in front of the piston affects the whole deformed area and that extrusion starts during this time interval.

Figure 5. Displacement of the nodes of the passive grid during the interval 33-58 $\mathrm{min}$ in Experiment 1.

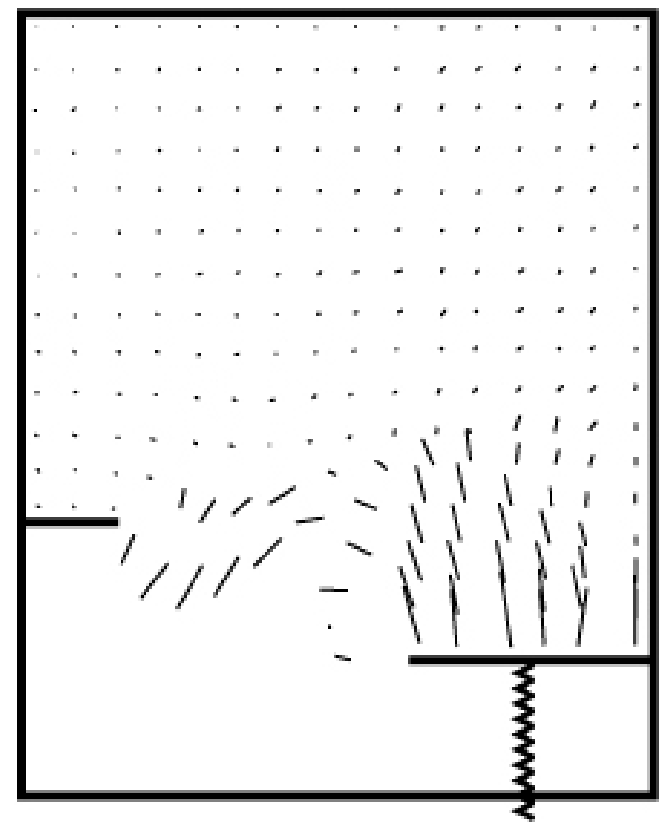

The strike-slip faults which accommodate extrusion link preexisting normal faults of the stretched domain north of the western arc with preexisting thrusts situated in the shortened area in front of the piston (Figure 3). Strike-slip faults always appear after the thrust and normal faults. They result from the convergent growth of both normal and thrust faults. The position of strike-slip faults accommodating extrusion thus appears to be controlled by the location of the thrust and normal faults which developed in the shortened and stretched areas respectively.

To investigate this hypothesis, two different experiments were conducted. First, we conducted an experiment with the same sand and silicone densities as in Experiment 1 but with a larger free boundary (Experiment 2, Table 1). In this experiment the size of the stretched zone is very large compared to the size of the shortened area, and the orientation of dextral strike-slip faults is very different from that in Experiment 1, with lateral faults now oriented NW-SE rather than E-W, joining the northernmost grabens with the northernmost thrusts (Figure 6).

Second, we conducted Experiment 3, which has the same geometry as the reference experiment presented in Figures 3 and 4. The density of the sand and silicone, however, is now close to the density of the honey substrate (Table 1). In this experiment, gravity spreading does not occur, because forces arising from lateral density contrasts are not strong enough to break the sand layer (Table 1). When the piston starts, shortening is concentrated in front of it without any lateral escape, even though a preexisting fault had been introduced in the sand layer to force extrusion (Figure 7). This experiment indicates that lateral escape cannot develop in the continental lithosphere if there is no extension somewhere to enable it [see also Suzanne, 1991]. Using a finite element program to study the westward escape of 
Anatolia, Cianetti et al. [1997] also concluded that extensional stresses in the Aegean region are necessary to enable the extrusion of Anatolia.
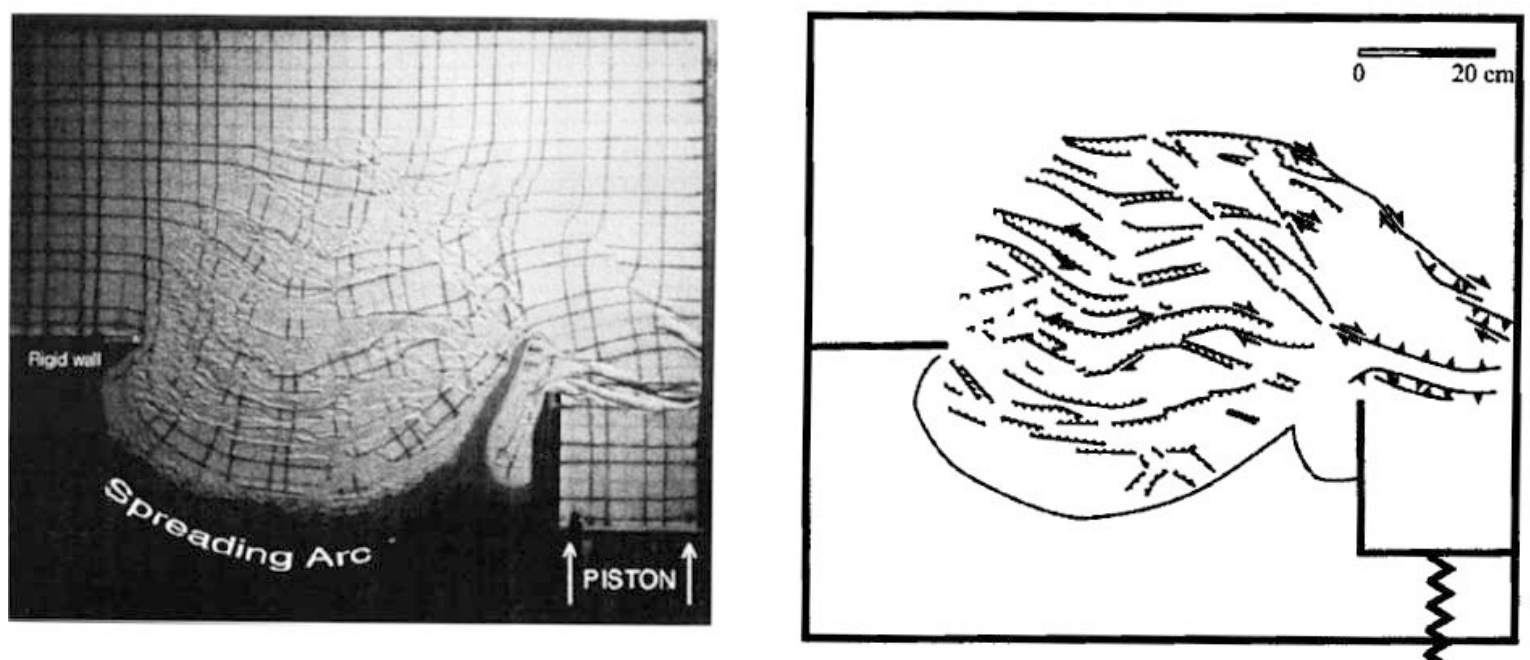

Figure 6. Experiment 2 after $145 \mathrm{~min}$. The rheological layering of this experiment is the same as that for Experiment 1 (Table 1). The main difference is the larger area where spreading occurs. Here the stretched zone is much more developed than the thrust area is. Dextral strikeslip faults accommodating lateral escape join the northernmost grabens with the thrust zone. These faults are oriented NW-SE in contrast to the E-W orientation observed in the experiment shown in Figure 3.
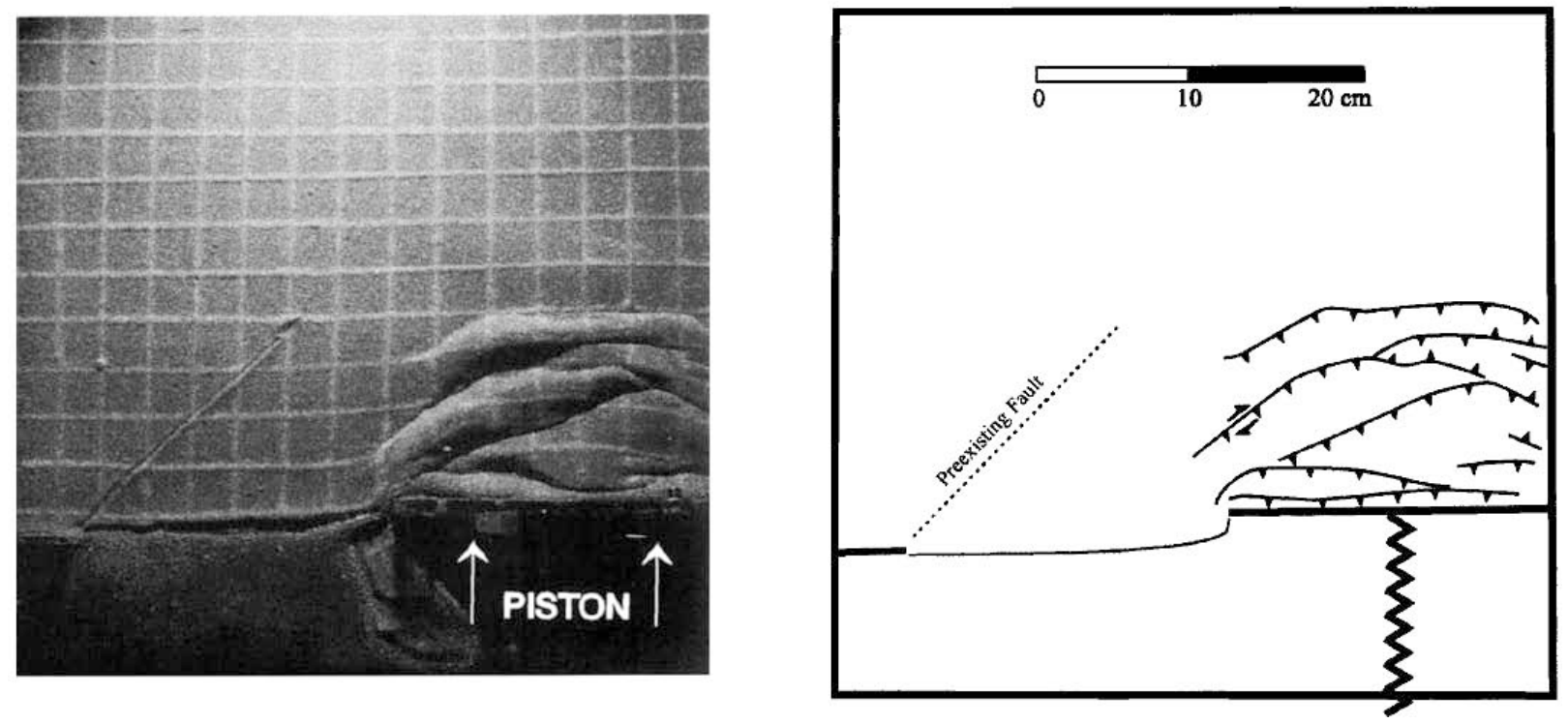

Figure 7. Experiment 3 after 76 min of shortening. The sand-silicone layer is heavier, and its density contrast with honey is low and does not exert enough force to break the sand layer and generate gravity spreading (Table 1). Shortening concentrates in front of the piston without any lateral escape, although a preexisting fault had been introduced in the model to facilitate extrusion.

As deformation induced by the piston movement continues (Experiment 1 after 83 min, Figure 3 ), the thrust zone in front of the piston propagates farther north of the stretched area. 
The new compressional structures which appear at this time do not link anymore with the extensional grabens. Although the new thrusts faults accommodate a small strike-slip motion, lateral extrusion does not develop from them. There is no more lateral escape, and the spreading arc moves again to the south (Figures 3 and 4).

\section{Discussion}

\subsection{The Required Conditions for the Development of Extrusion}

The most important implication of this experimental study is the indication that both the Arabia-Eurasia continental collision and the tensional deviatoric stresses arising from lateral density contrasts at the boundary between the Mediterranean oceanic plate and the Anatolian-Aegean continental domain, are likely requirements for the activation of the lateral escape of Anatolia (Figure 6) as was previously suggested by Suzanne [1991], Meijer and Wortel [1996], Cianetti et al. [1997], and Lundgren et al. [1998]. The extrusion rate of Anatolia increases by approximately $10 \mathrm{~mm} / \mathrm{yr}$ from east to west [Reilinger et al., 1997]. This increase indicates that the extrusion of the Anatolian plate probably is more controlled by the boundary conditions that prevail on the subduction zone than by the collision that occurs on the east. Experiments also indicate that the preexisting stretching of the Aegean lithosphere (which is older than the lateral escape of Anatolia [e.g., Gautier, 1995]) may exert a strong control on the position of the dextral strike-slip faults which accommodate extrusion.

\subsection{Deformation and Kinematics of Aegea and Anatolia}

In Experiment 1 the kinematics and deformation associated with the lateral escape of the sand-silicone layer are very similar to the present-day kinematics of the Anatolian-Aegean region as deduced from geodetic data (compare Figures 1 and 5) and seismicity. The western (Hellenic) arc moves to the SW as a whole, and within this arc the principal axes of the strain tensor are orientated roughly N-S (extension) and E-W (moderate shortening) (Figure 8). These directions correspond with those inferred from seismological or microtectonic data for the present-day deformation regime of the Aegean [e.g., Angelier et al., 1982; Mercier et al., 1989; Hatzfeld et al., 1990, 1993, 1995].

Figure 8. Principal axes of the strain tensors calculated for triangles of the passive grid for Experiment 1 after 58 min of deformation. Thin lines indicate extension, and thick lines indicate shortening.

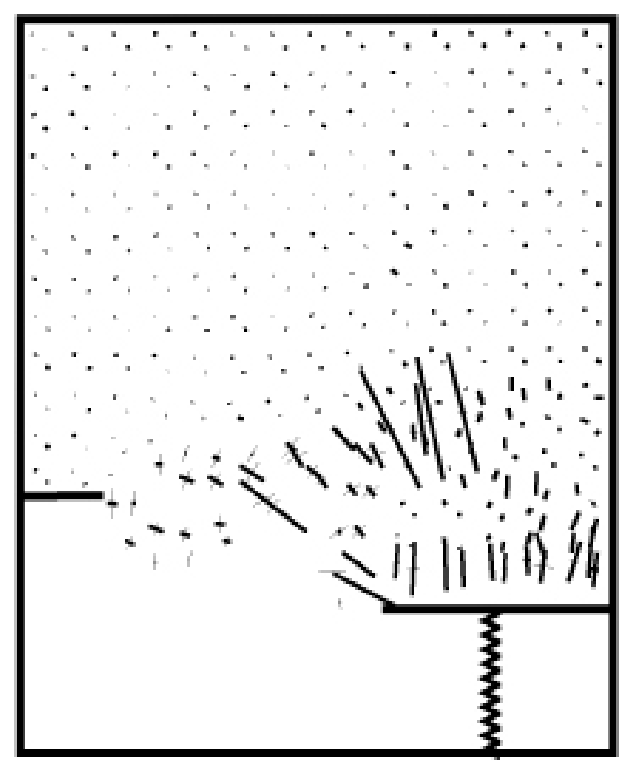


In the experiment the area situated north of the eastern arc (which corresponds in nature to central Anatolia) moves to the west. It does not show any N-S extension, because it corresponds to an intermediate domain situated between the collision zone imposed by the indentor (responsible for $\mathrm{N}-\mathrm{S}$ shortening) and the western arc where gravity spreading prevails (responsible for N-S extension). The intermediate position of central Anatolia between Aegea and the Arabia-Eurasia collision zone could explain why N-S extension is not observed there (there is no $\mathrm{N}-\mathrm{S}$ extension east of $31^{\circ} \mathrm{E}$ [Angelier et al., 1982]). It may also explain why the Cypriot arc does not move to the south and why the activity of this arc is so moderate compared with the activity of the Hellenic arc although the Mediterranean oceanic lithosphere is present south of both the Aegean and Cypriot arcs. On one hand, Cyprus is pulled to the south by the oceanic lithosphere, while on the other, it is pushed to the north by the motion of the neighboring Arabian plate.

\subsection{The Appearance of Two Distinct Spreading Arcs Above the Oceanic Plate.}

Most authors [e.g., Meijer and Wortel, 1997] modeling the deformation of the Aegean region consider that the Aegean lithosphere spreads over the subducted Mediterranean oceanic lithosphere between the Keffalinia fault and the Antalya Gulf (Figure 1). The reason why the Aegean arc ends near Keffalinia is clear: The Keffalinia fault corresponds to the transition from the oceanic subduction to the continental collision with the Apulian plate [e.g., Kahle et al., 1993 ; Baker et al., 1997]. Apulia opposes the advance to the SW of the Aegean plate, and GPS data show that Epirus, north of the Keffalinia fault, is stable with respect to Europe [e.g., Le Pichon et al., 1995] (Figure 1). In contrast, the eastern edge of the Hellenic arc south of Antalya does not correspond to any rheological change of the Mediterranean plate. Seismic refraction data show that the Mediterranean oceanic plate is present to the east as far as south Cyprus and the South Levantine Basin [Makris et al., 1983; Makris and Stobbe, 1984].

The boundary conditions that most workers adopt to reproduce the formation of the Antalya Gulf (no N-S motion of the southern boundary of the Anatolian plate east of Antalya; see, for instance, the work of Hatzfeld et al. [1997] or Meijer and Wortel [1997]) is convenient to get the eastern boundary of the Hellenic arc near Antalya. In reality, however, the same boundary conditions should apply south of the Aegean and Cypriot arcs. Then, such conditions cannot be invoked to explain the formation of the Antalya Gulf. Experiment 1 shows that the initial geometry of the continental plate, before the start of the subduction of the oceanic Mediterranean lithosphere, may have resulted in the formation of two distinct spreading arcs on both sides of the Antalya Gulf.

\subsection{Rotations}

The finite rigid body rotations evidenced in our experiments may be compared to paleomagnetic data. Clockwise rotations develop in the western parts of the western arc in Experiment 1. They reproduce the recent clockwise rotations measured using paleomagnetism in continental Greece [Kissel and Laj, 1988] (Figure 1), although rotations are observed in the region north of the Keffalinia fault extending as far as Albania [Speranza et al., 1995]. A possible explanation for the rotations measured north of the Keffalinia fault may be that oceanic or partially oceanic lithosphere was subducting till recently below Albania : The NW boundary of the Hellenic subduction would have migrated to the south, from northern Albania 
to Keffalinia. This may explain the recent deformation reported by Moretti and Royden [1988] in the Hellenides, south of the Scutari-Pec fault (northern Albania), and the apparent contradiction between paleomagnetic and geodetic data: The rapid motions responsible for the rotations reported in Albania by Speranza et al. [1995] for the Neogene (Mio-Pliocene) may have stopped with continental collision.

In Experiment 1, counterclockwise rotations appear in the eastern parts of the western arc, while no rotation occurs in the western part of the eastern arc. This is consistent with the absence of recent (Miocene) rotation in the Taurides east of the Antalya Gulf, while the western side of the gulf records a $30^{\circ}$ counterclockwise rotation for the same period [Kissel and Laj, 1988; Kissel et al., 1993]. It is clear, however, that the amount of rotation we observe in the experiment is highly dependent on the initial geometry adopted for the model. The preMiocene geometry of the Anatolian-Aegean plate may not be similar to the geometry that we adopted here. This may explain why the rotations we observe in Experiment 1 in the southern part of the eastern arc do not correspond with the recent rotations measured in Cyprus. Measurements by Abrahamsen and Schönharting [1987] indicate that Cyprus displaced 1500 $\mathrm{km}$ to the north during the last $30 \mathrm{Myr}$, but rotated counterclockwise less than $20^{\circ}$ during the same period. Thus analogue experiments suggest that the different rotations measured on both sides of the Antalya Gulf may result from the initial geometry of the plate, which is responsible for the formation of the two spreading arcs.

\subsection{The North Anatolian Fault}

In experiments the dextral strike-slip motion which accommodates extrusion is generally distributed over several faults. In reality, however, the lateral escape of Anatolia is absorbed by the North Anatolian fault only. Le Pichon et al. [1995] show that the displacement vectors with respect to stable Europe for points of the Anatolian-Aegean plate are close to the vectors that would result from the rotation of a rigid plate around an Euler pole situated near the Nile delta. This means that the Anatolian-Aegean plate, as a first-order approximation, presently behaves as a rigid plate, namely, that its internal deformation is responsible for displacements smaller than the overall motion of the "plate" [Reilinger et al., 1997]. The experiments presented here cannot reproduce this observation. We do not obtain in our experiment any "rigid" plate which behaves like Anatolia. The reason for this difference between nature and experiment may result from the heterogeneity of the rheology of the continental lithosphere. We know that major lithospheric faults such as the North Anatolian fault concentrate deformation since they are much weaker than the surrounding continental lithosphere [e.g., Tapponnier et al., 1986; Rice, 1992]. In contrast, we have carried out experiments on homogeneous material to avoid introducing too many arbitrary assumptions. This suggests that the rigid plate behavior of Anatolia results from the weakness of the North Anatolian fault [Cianetti et al., 1997].

\section{Conclusion}

The experiments presented in this paper provide simple explanations for the present-day tectonics of the Anatolian-Aegean area, particularly for what concerns the existence of the two Hellenic and Cypriot arcs, and for the different rotations measured in paleomagnetism on each side of the Antalya Gulf [Kissel et al., 1993]. The experiments suggest that both the 
Arabia-Eurasia continental collision and the extension at the boundary between the European plate and the Mediterranean are necessary to generate the lateral extrusion of Anatolia in accordance with Suzanne [1991] or Cianetti et al. [1997]. The geometry of the extruded plate may be controlled by the size of the thrust zone to the east and also by the size of the stretched area to the west.

Acknowledgments. Analogue experiments were built in the Modelisation Laboratory of Géosciences Rennes. Many thanks to marvelous J.J.K. Kermarrec for his technical and friendly assistance. C. Faccenna and J.P.J. Reijs provided careful and constructive reviews of the manuscript. P. Molnar and B. Chouet helped us to improve the manuscript.

\section{References}

Abrahamsen, N., and G. Schönharting, Palaeomagnetic timing of the rotation and translation of Cyprus, Earth Planet. Sci. Lett., 81, 409-418, 1987.

Angelier, J., N. Lybéris, X. Le Pichon, E. Barrier, and P. Huchon, The tectonic development of the Hellenic arc and the Sea of Crete: a synthesis, Tectonophysics, 86, 159-196, 1982.

Armijo, R., B. Meyer, G.C.P. King, A. Rigo, and D. Papanastassiou, Quaternary evolution of the Corinth Rift and its implications of the late Cenozoic evolution of the Aegean, Geophys. J. Int., 126, 11-53, 1996.

Baker, C., D. Hatzfeld, H. Lyon Caen, E. Papadimitriou, and A. Rigo, Earthquake mechanisms of the Adriatic sea and western Greece: Implications for the oceanic subduction-continental collision transition, Geophys. J. Int., 131, 559-594, 1997.

Berckhemer, H., Some aspects of the evolution of marginal seas deduced from observations in the Aegean region, in International Symposium on the Structural History of the Mediterranean Basins, edited by B. Biju-Duval and L. Montadert, pp. 303-313, Technip, Paris, 1977.

Cianetti, S., P. Gasperini, M. Boccaletti, and C. Giunchi, Reproducing the velocity and stress fields in the Aegean region, Geophys. Res. Lett., 24, 2087-2090, 1997.

Davy, P., and P.R. Cobbold, Experiments on shortening of 4-layer model of the continental lithosphere, Tectonophysics, 188, 1-25, 1991.

England, P., G. Houseman, and L. Sonder, Length scales for continental deformation in convergent, divergent, and strike-slip environments: Analytical and approximate solutions for a thin viscous sheet model, J. Geophys. Res., 90, 3551-3557, 1985.

Gautier, P., Géométrie crustale et cinématique de l'extension tardi-orogénique dans le domaine centre-égéen; lle des Cyclades et d'Eubée (Grèce), Mem. 61, 430 pp., Géosci. Rennes, Univ. de Rennes, Rennes, France, 1995.

Gautier, P., and J.P. Brun, Ductile crust exhumation and extensional detachments in the central Aegean (Cyclades and Evvia islands), Geodin. Acta, 7, 1994.

Gautier, P., J.P. Brun, R. Moriceau, D. Soukoutis, J. Martinod, and L. Jolivet, Timing, kinematics, and cause of Aegean extension: A scenario based on a comparison with simple analogue experiments, Tectonophysics, in press, 1999.

Hatzfeld, D., G. Pedotti, P. Hatzidimitriou, and K. Makropoulos, The strain pattern in the western Hellenic arc deduced from a microearthquake survey, Geophys. J. Int., 101, 181-202, 1990.

Hatzfeld, D., M. Besnard, P. Hatzidimitriou, and K. Makropoulos, Microearthquake seismicity and fault plane solutions in the southern Aegean and its tectonic implications, Geophys. J. Int., 115, 799-818, 1993.

Hatzfeld, D., I. Kassaras, D. Panagiotopoulos, D. Amorèse, K. Makropoulos, G. Karakaisis, and O. Coutant, Microseismicity and strain pattern in northwestern Greece, Tectonics, 14, 773-785, 1995. 
Hatzfeld, D., J. Martinod, G. Bastet, and P. Gautier, Gravity spreading: A possible contribution to the geodynamics of the Aegean, J. Geophys. Res., 102, 649-659, 1997.

Jolivet, L., J.P. Brun, P. Gautier, and S. Lallemant, 3-D kinematics of extension in the Aegean from early Miocene to present: Insight from ductile crust, Bull. Soc. Geol. Fr., 165, 195-209, 1994.

Kahle, H.-G., M.V. Müller, S. Mueller, and G. Veis, The Kephalonia transform fault and the rotation of the Apulian platform: Evidence from satellite geodesy, Geophys. Res. Lett., 20, 651-654, 1993.

Kahle, H.-G., C. Straub, R. Reilinger, S. McKlusky, R. King, K. Hurst, G. Veis, K. Kastens, and P. Cross, The strain rate field in the eastern Mediterranean region, estimated by repeated GPS measurements, Tectonophysics, 294, 237252, 1998.

Kissel, C., and C. Laj, The Tertiary geodynamical evolution of the Aegean arc: A paleomagnetic reconstruction, Tectonophysics, 146, 183-201, 1988.

Kissel, C., O. Averbuch, D. Frizon de Lamotte, O. Monod, and S. Allerton, First paleomagnetic evidence for a postEocene clockwise rotation of the western Taurides thrust belt east of the Isparta reentrant (southwestern Turkey), Earth Planet. Sci. Lett., 117, 1-14, 1993.

Le Pichon, X., and J. Angelier, The Hellenic arc and trench system: A key to the neotectonic evolution of the eastern Mediterranean area, Tectonophysics, 60, 1-42, 1979.

Le Pichon, X., N. Chamot-Rooke, S. Lallemant, R. Noomen, and G. Veis, Geodetic determination of the kinematics of central Greece with respect to Europe: Implications for eastern Mediterranean tectonics, J. Geophys. Res., 100, 12675-12690, 1995.

Lister, G.S., G. Banga, and A. Feenstra, Metamorphic core complexes of Cordilleran type in the Cyclades, Aegean Sea, Greece, Geology, 12, 221-225, 1984.

Lundgren, P., D. Giardini, and R. M. Russo, A geodynamic framework for eastern Mediterranean kinematics, Geophys. Res. Lett., 25, 4007-4010, 1998.

Makris, J., and C. Stobbe, Physical properties and state of the crust and upper mantle of the Eastern Mediterranean Sea deduced from geological data, Mar. Geol., 55, 347-363, 1984.

Makris, J., Z. Ben Avraham, A. Behle, A. Guinzburg, P. Giese, L. Steinmetz, R.B. Withmarsh and S. Eleftheriou, Seismic refraction profiles between Cyprus and Israel and their interpretation, Geophys. J. R. Astron. Soc., 75, 575-591, 1983.

McKenzie, D., Active tectonics of the Mediterranean region, Geophys. J. R. Astron. Soc., 55, 109-185, 1972.

Meijer, P.T., and M.J.R. Wortel, Temporal variation in the stress field of the Aegean region, Geophys. Res. Lett., 23, 439-442, 1996.

Meijer, P.T., and M.J.R. Wortel, Present-day dynamics of the Aegean region: A model analysis of the horizontal pattern of stress and deformation, Tectonics, 16, 879-895, 1997.

Mercier, J.L., D. Sorel, P. Vergely, and K. Simeakis, Extensional tectonic regimes in the Aegean basins during the Cenozoic, Basin Res., 2, 49-71, 1989.

Moretti, I., and L. Royden, Deflection, gravity anomalies and tectonics of doubly subducted continental lithosphere: Adriatic and Ionian Seas, Tectonics, 7, 875-893, 1988.

Noomen, R., B.A.C. Ambrosius, D.C. Kuyper, G.J. de Mets, B. Overgaauw, T.A. Springer, and K.F. Wakker, Crustal deformation in the Mediterranean area computed from space-geodetic observations, Eos. Trans. AGU, 75 (16), Spring Meet. Suppl., 115, 1994.

Oral, B., Global positioning system (GPS) measurements in Turkey (1988-1992) : Kinematics of the Africa-ArabiaEurasia plate collision zone, Ph.D. thesis, 344 pp., Massachusetts Institute of Technology, Cambridge, Mass.,1994.

Reilinger, R.E., S.C. McClusky, M.B. Oral, R.W. King, M.N. Toksoz, A.A. Barka, I. Kinik, O. Lenk, and I. Sanli, Global positioning system measurements of present-day crustal movements in the Arabia-Africa-Eurasia plate collision zone, J. Geophys. Res., 102, 9983-9999, 1997. 
Rice, J.R., Fault stress states, pore pressure, distributions, and the weakness of the San Andreas Fault, in Fault Mechanics and Transport Properties of Rocks, edited by B.E.T.F. Won, pp. 475-503, Academic, San Diego, Calif., 1992.

Sonder, L.J., and P.C. England, Effects of a temperature-dependent rheology on large-scale continental extension, J. Geophys. Res., 94, 7603-7619, 1989.

Speranza, F., I. Islami, C. Kissel, and A. Hyseni, Paleomagnetic evidence for Cenozoic clockwise rotation of the external Albanides, Earth Planet. Sci. Lett., 129, 121-134, 1995.

Suzanne, P., Extrusion latérale de l'Anatolie: géométrie et mécanisme de la fracturation, Ph.D. thesis, 262 pp., Rennes Univ., Rennes, France, 1991.

Tapponnier, P., G. Peltzer, and R. Armijo, On the mechanics of the collision between India and Asia, in Collision Tectonics, vol. 19, edited by M.P.Coward and A.C. Ries, Geol. Soc. Spec. Pub., 19, 115-157, 1986.

Veis, G., H. Billiris, B. Nakos, and D. Paradissis, Tectonic strain in Greece from geodetic measurements, Acad. Sci. of Athens, 67, 129-166, 1992. 